\title{
Advanced Experience and Enlightenment of American College Emergency Management
}

\author{
Shuzhi Yao ${ }^{1,}$, Tingting Jia ${ }^{2, b}$ \\ ${ }^{1}$ Shaanxi University of Science \& Technology, Xi'an, Shaanxi, 710021 \\ a email, ${ }^{b}$ email
}

Keywords: United States; Universities, Emergencies, Emergency Management

\begin{abstract}
Central Leading Group deepening reforms comprehensively the 15th meeting of building world-class university requirements, and security and stability for our country's colleges and universities to build the grand goal of first-class university meaningful. The United States has a world-class level in the University of emergency management, by analyzing the advanced experience of the United States, the College of Emergency Situation management and emergency conditions, perfecting the national legal education system, establish and try to deal with prevention, prevention-oriented management philosophy, and to make recommendations interregional joint development of information systems in three aspects.
\end{abstract}

\section{Introduction}

With the advent of higher education popularization quietly turning point, bringing large-scale development of our universities' crisis gradually horizon, sensitive social point of imminent risk, slightly negligent mistake, is likely to form a broad social impact and risk systems. Suicide Prevention Research Center of Shandong University (Centre for Suicide Prevention and Research, Shandong University) researchers and Tan Ping Fang Tang, Chinese University of suicidal ideation and social networks, the role of coping strategies to reduce suicide risk on the commencement of the study, which Research is currently the largest Chinese college students about suicidal ideation. [] They investigated six colleges and universities in Wuhan City, is up to 5972 the number of investigators. Survey shows that respondents with suicidal ideation were as high as $16.39 \%$. College group events, lending the campus network, campus theft, fire and other emergencies after another, campus security and stability faced with severe challenges. College how to deal with the revolution, has become our experts, university administrators urgent problem. Western countries, especially the advanced experience of the American College of Emergency Management provides a useful reference for China.

\section{Advanced Experience of American Universities Emergency Management}

Foreign Universities for Research on Emergency Management began in the 1980s, in the United States, also known as emergency crisis, crisis management theory has matured in the United States. Under the guidance of crisis management policy of the US government, the university formed a relatively mature emergency management mechanism. Stones from other hills, can learn. American colleges and universities to respond to emergencies, there are many advanced experience.

First, the legal system is sound, so that the legislation norms, strict law enforcement. United States attaches great importance to the work of higher education legislation, promulgated the first "Higher Education Act" in 1965, after several revisions, through constant revision to achieve a sustained and effective, the purpose of strengthening the force of law. The United States has been a world-class legal system and the authority of law enforcement agencies. On the one hand, the state developed a set of informative, accountability and targeted Emergency Management Act, such as "Campus Security Act", "crisis planning Useful Information: School and Community Guidelines", "Family Education and Privacy Act powers." other laws and regulations. While the humanitarian care, emergency training, etc. into the legal system. On the other hand, the power crisis management mechanism from the current law, an administrative body is not affiliated with, or 
without any special rights conferred an administrative department. American higher education has the following administrative features: Federal coordination and management, specifically responsible for the states, university autonomy.

Second, adhere to both response and prevention, prevention-oriented management philosophy. US government to establish an effective means of prevention is seen as a conscious control of the situation to expand. Threat Warning System according to the Ministry of Education Department of Homeland Security five countries (The Homeland Security Advisory System) developed for all types of emergency contingency plans at all levels. "Useful Information Crisis Planning: School and Community Guide," a book that, in resolving the crisis the most advanced concepts is to adhere to prevention. Individual states to develop contingency plans, the Federal Ministry of Education, states are required to provide emergency funding plan. Moreover, part of the American College of security report shows that establish prevention awareness plays an important role in emergency management. In view of this, American universities through the creation of a crisis management courses, establish the campus police system, strengthen education and training to improve students' awareness of prevention.

Third, pay attention to the construction of information, maximize system value. Reliable information systems, is a key factor to deal effectively with emergencies. According to the US official statement, the United States more than $90 \%$ of the emergency information is publicly available, and can not be disclosed due to classified information less than $10 \%$. Collected by government departments trunked radio network, satellite communications and other facilities to observe and analyze the information in order to play prevention first, the role of advance preparation. [] Moreover, states, major cities are equipped with emergency operation control center, 24 hours continuous operation, equipped with wireless communications cluster networks, cable television and other advanced techniques to monitor, aggregate, analyze the potential risk information. The school also established a reliable communication network, and the acquisition of a crisis situation required alternate communications equipment, communications capabilities from time to time to review the needs of the school's ability to match the time of crisis.

\section{Emergency Management Enlightenment in American College}

Domestic universities Emergency Management Zhoubei Long started in the 1994's "Crisis On China Education", has only 20 years, is still in the exploratory stage. Universities in our country there is a big worry of emergency management. From the legal point of view, construction, China's legislative process is slow, the mechanism is still not perfect; from the management philosophy point of view, China's heavy emergency response than prevention, not yet possible trouble; from information technology, China's information systems behind access to information means tradition. To reverse the situation, we should identify the short board, to address the issue, establish a College of Emergency management of the new ideas, new thinking in China.

First, the United States colleges and universities harsh law, the rule of law education in our country should be managed into the national education system, so that within the rule of law in the heart, the outside of the line. Any law is the product of a certain stage of social development. After 2003, "SARS", China's substantial research universities have begun emergency management, short-term study course. Currently, the face of the new situation at home and abroad, new issues, the current "constitution", "Emergency Response Law of the People's Republic of China", "Higher Education Act", "Student Injury Treatment" and exhibit relatively lag, the performance against not strong, legal liability is not clear, instructive than the specific operation and other issues. Although local governments have issued such as "Shaanxi Province, school health supervision guidance", "Sichuan Province school safety management approach" and other ways to respond to emergencies, but mostly administrative documents, the legal effect is not strong. In addition, it affected our management system, the Government College as no administrative authority of the executive branch to look at, so that colleges and universities has not formed its own independent corporate governance structure. []

National long-term stability of the rule of law is the basic guarantee, the party's eighteen Fourth 
Plenary Session presented comprehensively promote the rule of law, rule of law education into the national education system and spiritual civilization to create content. Thus, the state, local governments and universities should be the premise of the rule of law and law school, and the full implementation of the "people-oriented" scientific concept of development, and constantly improve the legal system. On the one hand, "Emergency Response Law of People's Republic of China", "Higher Education Act" and other laws introduced not long, more imperfections can be combined with new situations and new problems develop appropriate implementation details, the introduction of "sudden Universities events and emergency management, "" campus security Act "and other laws to make legal gap, truly advance the rule of law. On the other hand, to encourage local governments and authorities in the region in line with the actual introduction of the "local emergency management" relevant regulations, to place the current law does not involve the supplement. Colleges and universities should burst at the national, local incident response based on the Basic Law, formulate rules for emergencies universities of emergency management, and constantly improve the campus emergency management regulations.

Second, the United States insists prevention-oriented management philosophy, China should also build a new model of emergency management, prevention play a leading role. "Book of Changes" spoke of "security and forget danger, save and forget death, to know and forget the chaos." That is to warn you to establish a sense of urgency. China today is in a risk society, but we need to establish risk awareness, and enhance the predictability of crisis. Currently, countries and all provinces, municipalities and autonomous regions, the university basically forming a contingency plan, but the operability, effectiveness remains to be tested. Thus, state and local governments improve emergency plans at the same time, should actively prepare "emergency prevention manual" to guide the region's schools emergency prevention and response. As far as possible under the provincial Department of Education issued a document requiring all colleges and universities at least once each semester experiential exercises, the university through the issuance of brochures, relevant courses, etc., to form a "every few days" to carry out emergency drills situation. Universities can choose drill mode, but the program required to submit provincial education department, before implementation approved. Secondly, the influence of traditional examination-oriented education, university teachers and students neglect inertia preventive education, some colleges and universities and even the existence of "unexpected events will come sooner or later," "prevention work too difficult" and other negative emotions, resulting in prevention work more passive. In response, led by the Ministry of Education, prevention ability Universities Emergency Training course an important reform measures as a take compulsory curricular and extra-curricular practice of combining forms, and to develop criteria to assess learning outcomes. Finally, university teachers and students raise awareness of the crisis is still imparting knowledge-based, although occasionally invite professionals to teach prevention knowledge, escape skills, but students failed to get an intuitive experience, with little success. It is suggested that colleges and universities each semester to organize a joint exercise to defend the department and the public security department, assignment of learning, improve the professional level of staff security and emergency management systems. While establishing learning pressure, mental stress, economic stress, emotional stress, the repository of special groups of student employment pressure, always concerned about student dynamic.

Third, the US emphasis on information system construction, our country should be balanced funding for colleges and universities to achieve inter-regional cooperative information systems construction. General Secretary Xi Jinping 'national network and information security forum on "his speech said:" We want to accelerate the construction of critical information infrastructure security system. "On the one hand, the state should attach great importance to the construction of information systems, information technology Ecological Construction ring. Zhengwuzhuanwang perfect platform for emergency information reporting system, full information sharing through a dedicated radio network to send messages to universities, families and enterprises and institutions, forming a huge network to respond to emergencies emergency information management system. While efforts to develop a comprehensive emergency response software, emergency communication system, the establishment of a unified, efficient network of emergency management system, to 
solve the problem of a unified emergency management system is not formed, the local government to avoid selective submit emergency information, resulting in higher authorities access to information is not true. Such as the application of GIS in Emergency Management (GIS) to master the crisis information is much important. On the other hand, the state financial expenditure should be balanced and universities, development of urban and regional universities, colleges and universities set up special funds for the construction of information systems through financial grants. Universities use special funds to purchase a high level of emergency rescue equipment, technical support resources to provide reliable technical support prevention and respond to emergencies, to improve the current part of the region, the lack of emergency situation information systems and universities, to change the traditional manual collection, analysis, judged way risk information to build a strong campus security wall.

Comrade Deng Xiaoping visited the South in 1992 an important conversation, said: "I am afraid for three decades, we will form a set of more mature in all respects, more stereotyped system." Emergency Management in Chinese Universities It is also true, although currently there are many problems, but as long as we proceed from reality, continue to promote institutional innovation, will be able to create a College of emergency management model with Chinese characteristics.

\section{References}

[1] Tang F, Qin P (2015) Influence of Personal Social Network and Coping Skills on Risk for Suicidal Ideation in Chinese University Students PLoS ONE 10 (3): E0121023 doi: 10.1371 / journal.pone.0121023.

[2] Shan Chunchang. Emergency Management: Chinese characteristics, mode of operation and practice [M]. Beijing Normal University Press, 2011, p. 45.

[3] Yao Shuzhi. Local Colleges emergency management research [M]. Higher Education Press, 2016, page 4. 